\title{
Anterior Parietal Artery
}

National Cancer Institute

\section{Source}

National Cancer Institute. Anterior Parietal Artery. NCI Thesaurus. Code C32101.

The artery that delivers blood to the anterior portion of the parietal lobe. 